\title{
Microwave Irradiated Novel Mesoporous Nickel Oxide Carbon Nanocomposite Electrodes for Supercapacitor Application
}

\section{Rakesh Kumar Thida}

Jawaharlal Nehru Technological University Hyderabad Institute of Science \&amp; Technology

Shilpa Chakra CH ( $\nabla$ shilpachakra.nano@jntuh.ac.in )

Jawaharlal Nehru Technological University Hyderabad Institute of Science \&amp; Technology https://orcid.org/0000-0001-9556-712X

\section{Madhuri S}

Jawaharlal Nehru Technological University Hyderabad Institute of Science \&amp; Technology

\section{Sai Ram E}

Nanospan India Pvt Ltd

\section{Ravi K}

ARCl: International Advanced Research Centre for Powder Metallurgy and New Materials

\section{Research Article}

Keywords: Electrochemical, reduced GO., Supercapacitor, Specific capacitance, Energy density

Posted Date: March 22nd, 2021

DOl: https://doi.org/10.21203/rs.3.rs-330644/v1

License: (c) (i) This work is licensed under a Creative Commons Attribution 4.0 International License.

Read Full License

Version of Record: A version of this preprint was published at Journal of Materials Science: Materials in Electronics on July 7th, 2021. See the published version at https://doi.org/10.1007/s10854-021-06547-5. 


\title{
Microwave Irradiated Novel Mesoporous Nickel Oxide Carbon Nanocomposite Electrodes for Supercapacitor Application
}

\author{
T. Rakesh Kumar', CH. Shilpa Chakra' ${ }^{1 *}$, S. Madhuri', E. Sai Ram², K. Ravi ${ }^{3}$. \\ ${ }^{I}$ Center for Nanoscience and Technology, Institute of Science and Technology, JNTU Hyderabad, T.S-500085. \\ ${ }^{2}$ Nanospan India private limited, Patancheru, Hyderabad, T.S -502319. \\ ${ }^{3}$ Centre for Carbon Materials, International Advanced Research Centre for Powder \\ Metallurgy \& New Materials (ARCI), Hyderabad, T.S -500005.
}

E-mail: shilpachakra.nano@jntuh.ac.in ORCID: 0000-0001-9556-721X

The present work accentuates the aspects of electrochemical analysis determined by Cyclic Voltammeter(CV), especially enhancement in Supercapacitor's specific capacitance and energy density. In this work, Nickel Oxide (NiO) and Nickel Oxide @ reduced Graphene Oxide (NiO@rGO) nanocomposite materials using as electrodes synthesized by the Microwave irradiation method. Performance of the synthesized material further characterized using X-Ray diffraction (XRD), Fourier Transform Infrared Spectroscopy (FTIR), Field-Emission Scanning Electron Microscope (FE-SEM), BET(Brunauer-EmmettTeller) specific surface-area, Thermo Gravimetric Analysis (TGA), and CV. Electrochemical performance of active material at three different molarities (2M, 4M \& 6M) of potassium hydroxide $(\mathrm{KOH})$ as an electrolyte is analyzed and observed decline in specific capacitance for synthesized nanocomposite materials in a lower state of electrolyte concentration. Accordingly, Specific capacitances at $1 \mathrm{~A} / \mathrm{g}$ are $270 \mathrm{~F} / \mathrm{g}, 395 \mathrm{~F} / \mathrm{g}$ at $1 \mathrm{~A} / \mathrm{g}$ current density, and Energy densities of $10.2 \mathrm{Wh} / \mathrm{Kg}, 17.55 \mathrm{Wh} / \mathrm{Kg}$ are observed for $\mathrm{NiO}$ and $\mathrm{NiO} @ \mathrm{rGO}$ respectively at $6 \mathrm{M} \mathrm{KOH}$.

\section{Graphical Abstract}

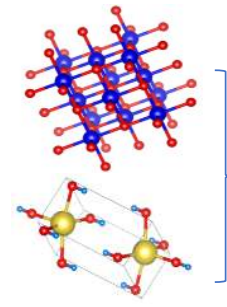

Nickel precursor
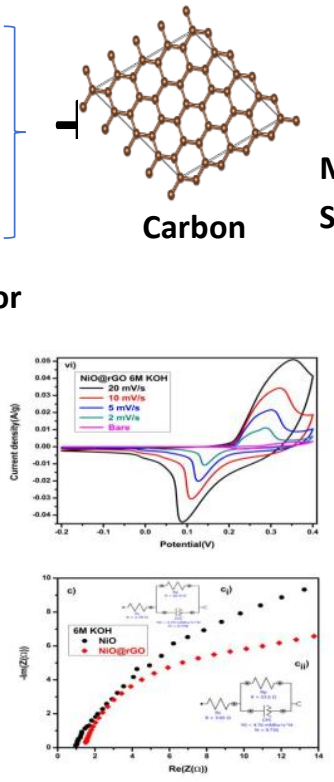

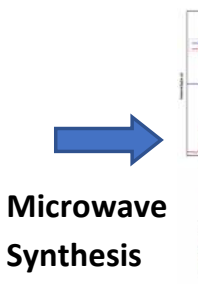

Synthesis

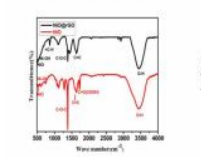

Spectroscopic study

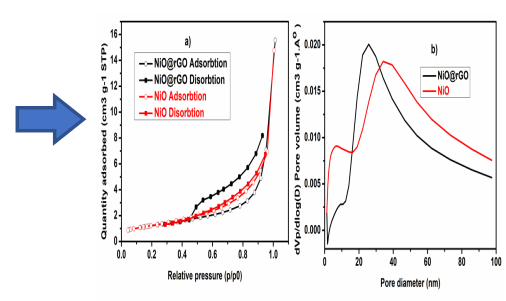

Specific surface area
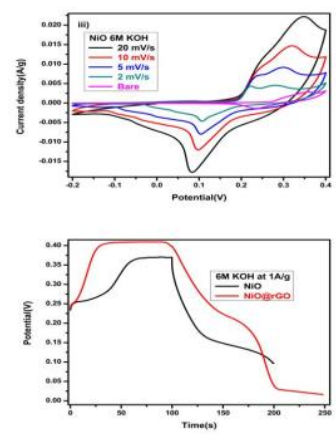

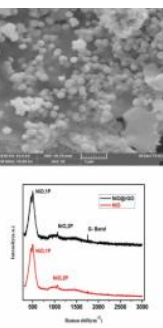

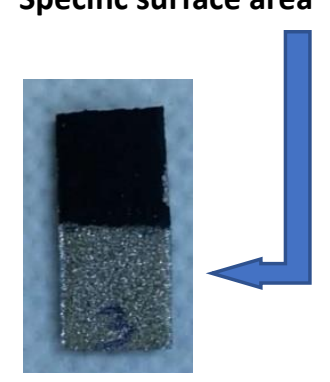

Working Electrode

\section{Electrochemical Analysis}

Keywords: Electrochemical, reduced GO., Supercapacitor, Specific capacitance, Energy density. 


\section{Introduction:}

In the present time, sustainable energy storage devices play a vital role in the modern developing society. The improvement in clean and sustainable energy is leading to growing needs for electrical storage devices. Due to these batteries and Supercapacitors (SCs) are widely investigated by the research community. SCs are in the front-line of electrochemical energy storage systems designed with anode, cathode, and electrolyte sandwiched between them, separated by an insulator, and current collectors connect them externally ${ }^{[1]}$.

The present research focuses on Eco-friendly low toxic metal oxide electrode materials for SCs. Nano-sized $\mathrm{NiO}$ has caught considerable attention recently due to its low cost and Pseudo capacitive behavior, but the high resistivity of $\mathrm{NiO}$ is a drawback for practical applications in SCs ${ }^{[2]}$. To address the challenges, carbon materials with high conductivity have introducing to prepare nano $\mathrm{NiO}$ carbon composites. Reduced graphene oxide( $\mathrm{rGO})$ is an excellent candidate for manufacture new complexes containing sp2 -hybridized carbon atoms with a twodimensional (2D) structure. rGO generates keen interest from researchers because of its specific characteristics such as high conductivity, large surface area, and stability in different chemical environments ${ }^{[3]}$. The metal oxide rGObased nanocomposite electrodes can quickly transfer electrons across the energy bands due to the graphene's high work function, which encourages materials' reactivity. Versatile routes such as solution combustion, chemical precipitation, and hydrothermal techniques regularly produce nano metal oxide materials ${ }^{[4]}$. The microwave irradiation technique has advantages such as increased reaction kinetics, evenly distributed particles, agglomeration dissemination, and this technique reduces the reaction time and suppresses side reaction and thus enhances the reproducibility ${ }^{[5]}$. It well understood that the working potential of the SCs is dependent on the electrochemical behavior of the electrolytes; aqueous electrolytes can achieve both high capacitance and ionic conductivity. Although $\mathrm{KOH}$ electrolytes widely used for SCs applications, in the literature, commonly $1 \mathrm{M}^{[6]}, 2 \mathrm{M}^{[7]}, 3 \mathrm{M}^{[8]}$, $5 \mathrm{M}^{[9]}$, and $8 \mathrm{M}^{[10]}$ concentrations. We have used $\mathrm{NiO} @$ rGO nanocomposite as an active electrode material and studied the influence of $\mathrm{KOH}$ concentrations $(2 \mathrm{M}, 4 \mathrm{M}$, and $6 \mathrm{M})$ on the electrochemical behavior in detail by adjusting the electrolyte concentration with the objective to draw a reliable output ${ }^{[11]}$.

\section{Experiment:}

Materials: Nickel nitrate hexahydrate, Sodium hydroxide, chemical grade from Finar make and Reduced Graphene Oxide with research-grade were brought from Platonic Nanotech Pvt Ltd India. All the chemicals are used directly without any further purification, and Distilled(DI) water used as an aqueous medium.

Synthesis of Nanocomposites: Synthesis of NiO@rGO nanocomposites: $0.1 \mathrm{M}$ Nickel nitrate hexahydrate were dissolved in $100 \mathrm{ml}$ of DI water under constant stirring for $15 \mathrm{~min}$ at room temp. A further $0.5 \mathrm{wt} \%$ of reduced Graphene Oxide(rGO) was added to the above solution and continued stirring for 30min until the homogeneous mixer formed. However, to maintain the solution at $\mathrm{pH}=7,0.5 \mathrm{M}$ sodium hydroxide was added dropwise to the above mixer. This mixer was then subjected to microwave irradiation using LG MC2846SL with an operating frequency of $2.45 \mathrm{Ghz}$, power of $900 \mathrm{~W}$, and $10 \mathrm{~min}$ of exposure time. The final material obtained was dried at $60^{\circ} \mathrm{C}$ in the hot-air oven for $12 \mathrm{~h}$, the resulting powder NiO@rGO nanocomposite was heated at $350^{\circ} \mathrm{C}$ in a muffle furnace for 3hours.

Electrode preparation: Working electrodeprepared using synthesized nanocomposites, $80 \%$ of active material (NiO and $\mathrm{NiO} @ \mathrm{rGO}$ ), 10\% of Polyvinylidene 
Fluoride (PVDF), and 10\% of Activated carbon material. PVDF is resistant to adverse weather conditions over a wide range of temperatures, outstanding chemical resistance to electrodes, and an organic binder. Activated carbon is used as a solvent to develop the surface area chemically active and limit the adsorbent in the electrode and electrolyte interface. The mixed active material, PVDF, and Activated carbon material compound made as a thick slurry using motor and pistle ${ }^{[5]}$ with few drops of NMP to coated on $1 \times 1 \mathrm{~cm} 2 \mathrm{Ni}$ foam substrate(purity $99.9 \%$, thickness $2 \mathrm{~mm}$, PPI (60-90)\%, pore size $0.05-$ $0.5 \mathrm{~mm}$.) uniformly and heat treatment given at $80^{\circ} \mathrm{C}$ for 12hours. The electrochemical analysis performed by a three-electrode system using a Metrohm Autolab PGSTA302N(Potentiostat / Galvanostat) equipment with NOVA 2.0.2 software.

\section{Characterization:}

Thermogravimetric(TG) analysis evaluated at a temperature ranging from $25-600^{\circ} \mathrm{C}$ heating rate $10^{\circ} \mathrm{C} / \mathrm{min}$ using EXSTAR TG/DTA6300. The structural properties of synthesized nanomaterials characterized by X-Ray Diffraction (XRD) Bruker D8 advance using $\mathrm{Cu} \mathrm{K}_{\alpha}$ $\left(\lambda=1.5418 \mathrm{~A}^{\circ}\right)$ as source with 2 theta ranging from $20-80^{\circ}$ at a scan rate of $0.5 \mathrm{~s}$. Fourier Transform Infrared(FTIR) spectra recorded using Bruker Alpha II, Raman spectroscopic analysis carried out using CRM 215 VIR. Morphology studies performed by Field-Emission Scanning Electron Microscope (FE-SEM) Zeiss instrument. Brunauer-Emmett-Teller(BET) Surface area and pore size distribution analyzed by BELSORP mini II.

\section{Results and Discussion:}

TG Analysis is used to obtain weight loss of material and verify the successful preparation of nanomaterials performed shown in Fig1(a). the mass changes observed in three steps Two samples indicated
Slight weight loss below $150^{\circ} \mathrm{C}$ due to the evaporation of adsorbed water molecule. While the temperature rises to $290^{\circ} \mathrm{C}$, there is a decomposition of $\mathrm{Ni}(\mathrm{OH})_{2}$ into $\mathrm{NiO}$. Weight loss absorbed is due to lattice water molecule evaporation, removal of residual sodium content, and organic matter decomposition. It speculated that nanoparticles calcined above $350^{\circ} \mathrm{C}$ are due to the $\mathrm{NiO} @ \mathrm{rGO}$, and particles calcined above $400{ }^{\circ} \mathrm{C}$ may be the mixture of $\mathrm{Ni}, \mathrm{NiO}$, and $\mathrm{NiO} @ \mathrm{rGO}$ nanocomposite ${ }^{[12]}$.

XRD patterns of rGO, $\mathrm{NiO}$, and $\mathrm{NiO} @ \mathrm{rGO}$ nanocomposite shown in Fig1(b). the broad peak absorbed at $26.1^{\circ}$ indicates (002) plane of bare $\mathrm{rGO}^{[13]}$ shown in Fig1(b'). Fig 1(b) shows five prominent peaks of $\mathrm{NiO}$ at 2Theta $37.2^{\circ}, 43.2^{\circ}, 62.9^{\circ}, 75.3^{\circ}$ and $79.4^{\circ}$ related to the

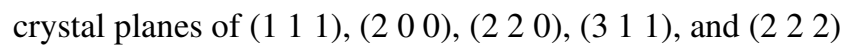
having cubic face structure with JC-PDS card no.78-0429 [5]. The representation of the rGO peak in NiO @ rGO nanocomposite prepared by the microwave irradiation method confirms the binary nanocomposite formation. No extra peaks observed in the XRD spectra of the prepared material clearly resemble the absence of any secondary peaks in the XRD patterns showing its purity. Average crystallite size calculates using the Debye-Scherer formula. The crystallite size is predicting by Peak width, which is perpendicular to planes. Different Theta positions the separation size and strain broadening analysis done by Williamson and Hall equation ${ }^{[14]}$. The average crystallite size is decreased the microstrain increased; this might be due to mechanical surface free energy of the metastable nanomaterials.

\section{Debye-Scherer Equation:}

$$
D=(k \lambda / \beta \cos \theta)
$$

$\mathrm{D}$ is average Crystallite size, $\mathrm{k}$ is Scherrer constant, $\lambda$ is a wavelength, $\beta$ is FWHM, $\theta$ is diffraction angle. 


\section{Williamson and Hall Equation:}

$$
\beta=\left(k \lambda / D^{*} \cos \theta\right)+(4 \varepsilon \tan \theta)
$$

$\mathrm{D}^{*}$ is average grain size, $\mathrm{k}$ is Scherrer constant, $\lambda$ is a wavelength, $\beta$ is FWHM, $\theta$ is diffraction angle, $\varepsilon$ is lattice strain.

The grain size measured from Williamson and Hall equation and Debye Scherrer equation for $\mathrm{NiO}$ and NiO@rGO values shown in Table 1.
Table1: Average Size and strain of Nanocomposite structures

\begin{tabular}{|l|l|l|l|}
\hline $\begin{array}{l}\text { Material } \\
\text { name }\end{array}$ & $\begin{array}{l}\text { Average } \\
\text { crystallite } \\
\text { size(D) }\end{array}$ & $\begin{array}{l}\text { Average } \\
\text { grain } \\
\text { size(D*) }\end{array}$ & $\begin{array}{l}\text { Lattice } \\
\text { strain }\end{array}$ \\
\hline $\mathrm{NiO}$ & $24 \mathrm{~nm}$ & $44 \mathrm{~nm}$ & 0.00131 \\
\hline $\mathrm{NiO} @ \mathrm{rG} 0$ & $17 \mathrm{~nm}$ & $36 \mathrm{~nm}$ & 0.00066 \\
\hline
\end{tabular}
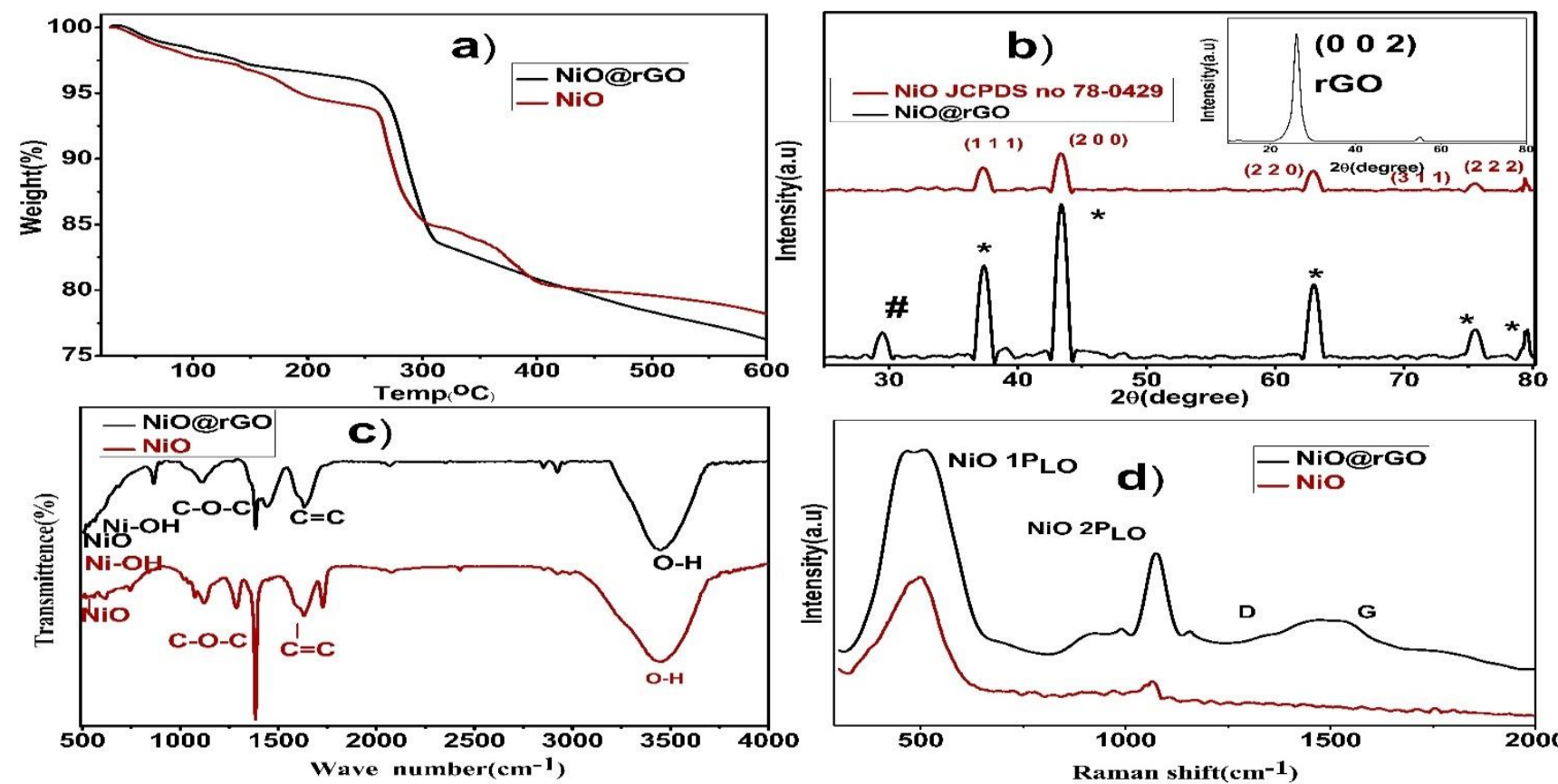

Fig1(a) TG spectra of NiO \& NiO@rGO (b) XRD patterns of NiO \& NiO@rGO (c) FTIR spectra of NiO \& NiO@rGO (d)

\section{Raman spectra of NiO \& NiO@rGO nanocomposites.}

FTIR performed to investigate metal behavior with carbon functional groups. Fig 1c shows the FTIR spectrum of irradiated microwave samples, i.e., $\mathrm{NiO}$ and $\mathrm{NiO} @ \mathrm{rGO}$ nanocomposite. The bare $\mathrm{NiO}$ nanomaterial shows distinct peaks at 520, 617, 1226, 1383.9, 1632, 3456 and similar peaks observed in $\mathrm{NiO} @ \mathrm{rGO}$ nanocomposite. The peak at $520 \mathrm{~cm}^{-1}$ indicates metal-oxygen bonding between $\mathrm{Ni}$ and $\mathrm{O}$ as vibration absorption bonding, peak at $1383.9 \mathrm{~cm}^{-1}$ is due to the presence of hydroxyl group attained from chemically adsorbed water molecule during the synthesis of nanostructures ${ }^{[13]}$. The peak around 1628 $\mathrm{cm}^{-1}$ is due to $\delta-\mathrm{H}_{2} \mathrm{O}$ bending vibration of the water molecule absorbed by material ${ }^{[15]}$. Incase of NiO@rGO nanocomposite, the transmission peak observed at $1645 \mathrm{~cm}^{-}$ ${ }^{1}$ corresponds to stretching vibration of $\mathrm{C}=\mathrm{C}$ aromatic link. The peak around $1070 \mathrm{~cm}^{-1}$ observed due to alkoxy and epoxy carbon-oxygen stretching vibration indicates binary nanocomposite formation of $\mathrm{NiO} @ \mathrm{rGO}^{[13]}$.

Raman Spectroscopy of $\mathrm{NiO}$ and $\mathrm{NiO} @ \mathrm{rGO}$ nanocomposites shown in Fig1(d). Two peaks are located 
at

$495 \mathrm{~cm}^{-1}$ and $1074 \mathrm{~cm}^{-1}$ observed in both spectra attributed to the one phonon(1P) longitudinal optical $\left(1 \mathrm{P}_{\mathrm{LO}}\right)$ and two phonons(2P) longitudinal optical $\left(2 \mathrm{P}_{\mathrm{LO}}\right)$ of $\mathrm{NiO}$ vibrational modes, respectively ${ }^{[2,16]}$. it provides the information of disorder and defects in carbon-based materials by the changes in the relative intensity of two main peaks as $G$ and $D^{[17]}$. The peaks located at approximately $\sim 1350 \mathrm{~cm}^{-1}$ and $\sim 1575 \mathrm{~cm}^{-1}$ correspond to $\mathrm{D}$ and $\mathrm{G}$ bonds of $\mathrm{rGO}$ symbolized as disorder and tangential bonds, respectively ${ }^{[18]}$. The peaks of $\mathrm{NiO}$ and $\mathrm{rGO}$ confirm the formation of $\mathrm{NiO} @ \mathrm{rGO}$ nanocomposite.

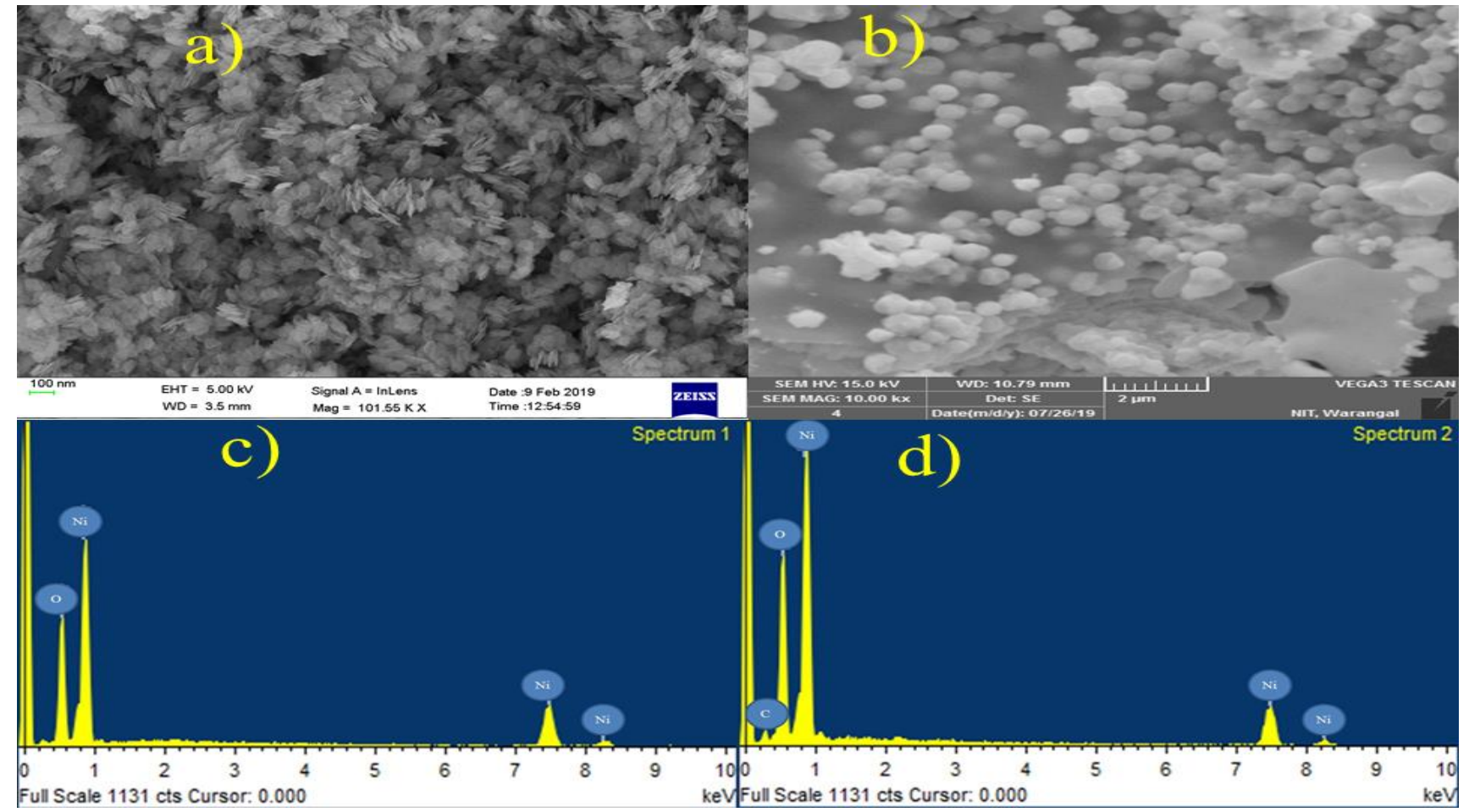

Fig2: (a) FE-SEM NiO b) FE-SEM NiO@ rGO c) EDAX NiO (d) EDAX NiO@ rGO

Morphology of the synthesized nanomaterial characterized by FE-SEM shown in fig2. It is observing that the material obtained exhibits nano circular plate-like structures ${ }^{[19]}$. The nano circular plate assembled, intercalated with their basal surfaces, and had a mean edge length of $\sim 60 \mathrm{~nm}$ and an average thickness of $\sim \mathrm{nm} 10$, also known as twin structural materials. In twin structural nanocrystalline materials, both grain size and twin-thickness decreased to the nanometer scale. Twin thickness significantly affects the deformation model of face-centered cubic structured materials, and it is unclear due to direct atomic-scale observations rarely acquired in experiments ${ }^{[20]}$.
The concentration of elements analyzed by Energy dispersive X-ray analysis(EDS or EDAX). Concentrations accompanied by a maximum of $\mathrm{Ni}$ along with $\sim 60 \%$ and $\mathrm{O}$ along with $\sim 40 \%$ of $\mathrm{NiO}$ nanostructure distributions. $\mathrm{Ni}$ along $\sim 60 \%$ and $\mathrm{O}$ along $\sim 39 \%$ and $\mathrm{C}$ along $<1 \%$ of distributions in the case of $\mathrm{NiO} @ \mathrm{rGO}$ nanocomposite structures. Finally, nanostructures were nano circular plates with uniform distribution, without agglomeration, and no impurity evidence in the composition ${ }^{[21]}$.

BET specific surface area analysis and porous study of $\mathrm{NiO}$ nanostructured\& $\mathrm{NiO} @ \mathrm{rGO}$ nanocomposite materials tested by nitrogen adsorption-desorption isotherms. As 
shown in Fig3, the result notified that both $\mathrm{NiO} \&$ NiO@rGO nanostructured materials are Type IV isotherm. An apparent hysteresis loop at a relative pressure (1-0.6) for $\mathrm{NiO} \&(1-0.45)$ for $\mathrm{NiO} @ \mathrm{rGO}$ shows the adsorption behavior of mesoporous materials. The specific surface area of $\mathrm{NiO} 0.94 \mathrm{~m}^{2} \mathrm{~g}^{-1}$, NiO@rGO $4.53 \mathrm{~m}^{2} \mathrm{~g}^{-1}$, Total pore volume $0.0085226 \mathrm{~cm}^{3} \mathrm{~g}^{-1}$ for $\mathrm{NiO} \& 0.018861 \mathrm{~cm}^{3} \mathrm{~g}^{-1}$ for $\mathrm{NiO} @ \mathrm{rGO}$ and mean pore diameter of $\mathrm{NiO}$ is $36.2 \mathrm{~nm}$, $\mathrm{NiO} @ \mathrm{rGO}$ is $16.7 \mathrm{~nm}$. An increase in the specific surface area leads to an enhancement in Electrochemical specific capacitance due to its direct effect on NiO@rGO nanocomposite electrode material's reaction sites. The Barrett-Joyner- Halenda (BJH) analysis shows a narrow pore size distribution centered at $46 \mathrm{~nm}$ for $\mathrm{NiO}$ and $22 \mathrm{~nm}$ for NiO@rGO. An increase in specific surface area, mean pore volume, and mesoporous diameter in NiO@rGO nanocomposite observed compared to $\mathrm{NiO}$ nanostructures lead to an improvement in electrochemical performance.
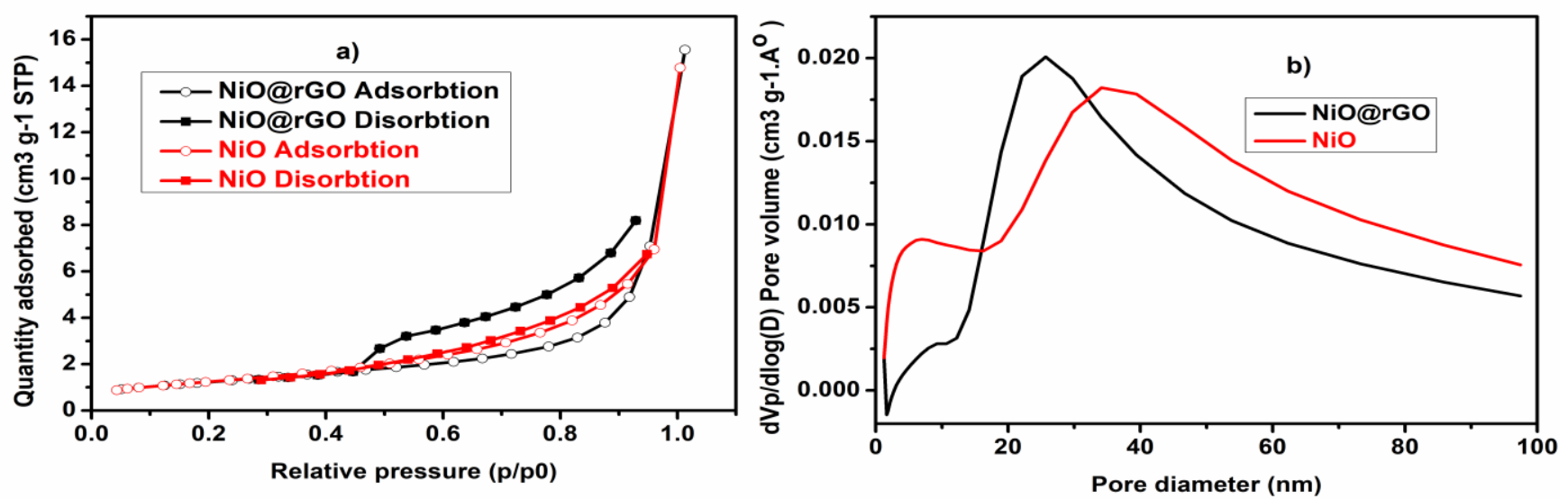

Fig 3: (a) N2 adsorption-desorption isotherm of NiO\& NiO@rGO (b) pore size distribution of NiO \& NiO@rGO

\section{Electrochemical Study:}

Cyclic voltammetry(CV) studies observed at 2,5,10 and $20 \mathrm{mV} / \mathrm{s}$ scan rates for $\mathrm{NiO}$ and $\mathrm{NiO} @ \mathrm{rGO}$ nanocomposites from $-0.2 \mathrm{~V}$ to $0.4 \mathrm{~V}$ as applied potential range with $2,4, \& 6 \mathrm{M} \mathrm{KOH}$ as an electrolyte shown in Fig4. A scan rate of $2 \mathrm{mV} / \mathrm{s}$ was observed from the analysis to have higher specific capacitance than other scan rates. It proposed that the scan rate is inversely proportional to Specific capacitance for both $\mathrm{NiO}$ and NiO@rGO nanocomposite.

The reduction peaks obtained at reverse/cathodic scanning from $\sim 0.1$ to $\sim 0.2 \mathrm{~V}$, oxidation peaks obtained at forward/anodic scanning from $\sim 0.3 \mathrm{~V}$ to $\sim 0.33 \mathrm{~V}$ for $2 \mathrm{mV} / \mathrm{s}$ scan rate, an increase in scan rate shows oxidationreduction peaks slightly shifted their potential values. Electrochemical behavior observed at 2,4,\&6M $\mathrm{KOH}$ as Electrolyte solutions notified that decreasing the electrolyte concentration decreases in specific capacitance.

The specific capacitance calculated from CV studies following formula :

$$
\mathrm{Cs}=\frac{\int \mathrm{Idv}}{2 \times \mathrm{m} \times \Delta V \times \mathbf{s}}
$$

Where Cs is Specific capacitance $(\mathrm{F} / \mathrm{g})$ $\mathrm{m}$ is mass of material coated on electrode $(\mathrm{mg})$ $\Delta \mathrm{V}$ is potential applied(V)and $\mathrm{s}$ is scan rate $(\mathrm{mV} / \mathrm{s})$. 

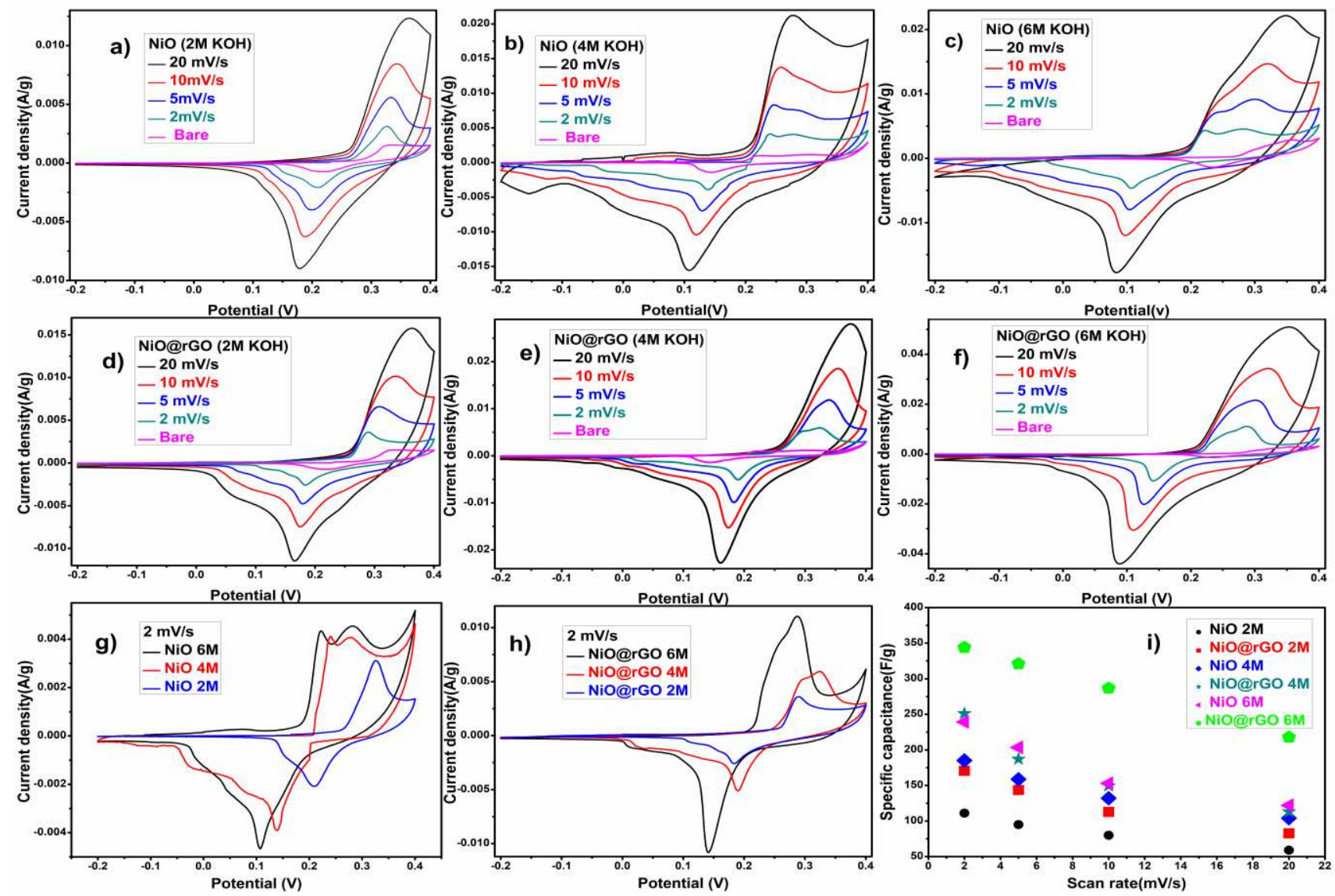

Fig4: a),b) and c) $\mathrm{CV}$ of $\mathrm{NiO}$ at $2,5,10$ and $20 \mathrm{mV} / \mathrm{s}$ Scan rates with $2 \mathrm{M}, 4 \mathrm{M}$ and $6 \mathrm{M}$ of $\mathrm{KOH}$ as electrolyte respectively d),e) and f) $\mathrm{CV}$ of $\mathrm{NiO} @ \mathrm{rGO}$ at $2,5,10$ and $20 \mathrm{mV} / \mathrm{s}$ Scan rates with $2 \mathrm{M}, 4 \mathrm{M}$ and $6 \mathrm{M}$ of $\mathrm{KOH}$ as electrolyte respectively g),h) CV of 20mV/s Scan rates of NiO\&NiO@ rGO respectively i)Specific capacitance Vs Scan rate

Electrochemical Impedance Spectroscopy (EIS) analysis observe for $\mathrm{NiO}$ and $\mathrm{NiO} @ \mathrm{rGO}$ nanocomposite at a frequency range of $0.1-100 \mathrm{kHz}$ with bias potential. Impedance measurements performed at $2,4,6 \mathrm{M} \mathrm{KOH}$ as an electrolyte showed in Nyquist plots Fig5 (a),(d),(g), respectively. The EIS data analyzed using a Nyquist Plot was a straight line in the low-frequency region and an arc in the high-frequency. The semicircle at high frequency suggests that interfacial charge-transfer resistance is significantly low because of the high conductivity. The linear shape indicates the purity of capacitive behavior, which implicates the ideal Supercapacitor. Fig5 shows $\mathrm{NiO}$ and $\mathrm{NiO} @ \mathrm{rGO}$ nanocomposite's equivalent circuits,
Rp indicates the charge transfer resistance, Rs indicates the solution resistance, and CPE is the Constant phase element. $\mathrm{Rp}$ relates to the electroactive surface area of the prepared electrode due to the Faradic redox process of the prepared electrodes involving in the exchange of $\mathrm{OH}-$ ions. $\mathrm{Rp}$ of $\mathrm{NiO} @ \mathrm{rGO}$ is $5.25 \Omega$, and $\mathrm{NiO}$ is $8.91 \Omega$ at $6 \mathrm{M} \mathrm{KOH}$ as an electrolyte. The diffusivity of the electrolyte-enhanced due to the structural and morphological surface area of NiO@rGO nanocomposite, reduced charge-transfer resistance of $\mathrm{NiO@rGO}$ nanocomposite gains the characteristics of the ideal capacitor. The capacitors in a real cell behave like a $\mathrm{CPE}$, has an exponent constant(N) of $<1^{[5]}$. 


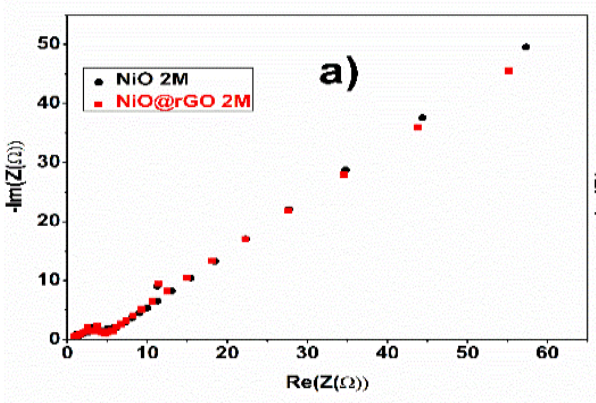

b)

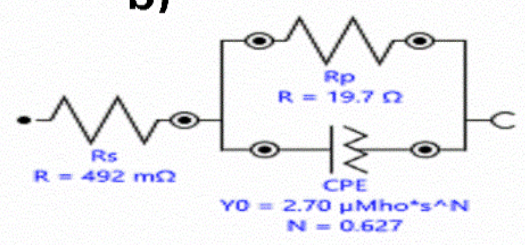

c)

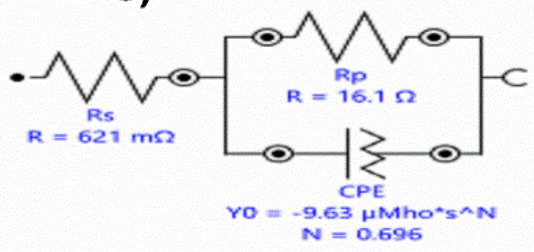

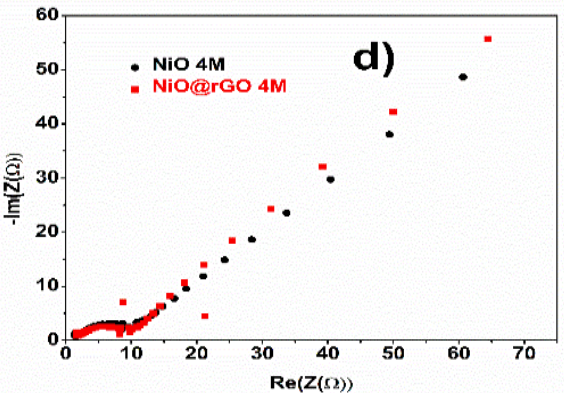

e)

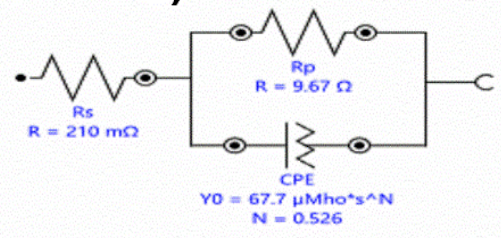

f)

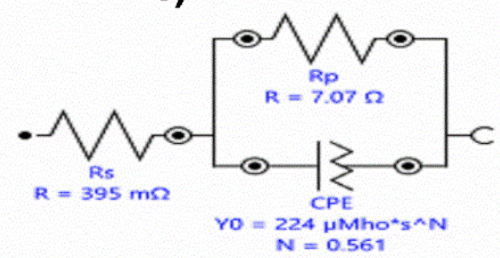

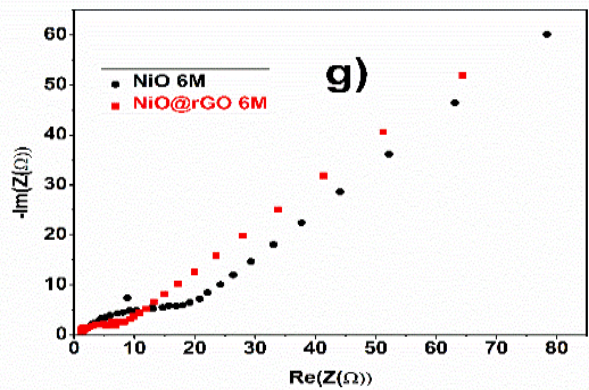

h)

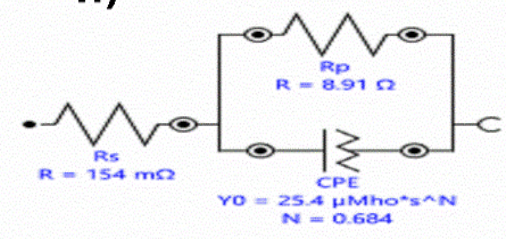

i)

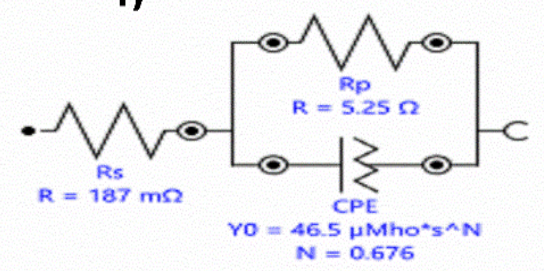

Fig5: (a)(d)(g) EIS study of NiO \&NiO@rGO at 2,4,6M KOH as an electrolyte respectively. (b)(e)(h) Equivalent circuit NiO. (c)(f)(i) Equivalent circuit $\mathrm{NiO} @$ rGO at 2,4,6M KOH as an electrolyte respectively.

Galvanostatic charge-discharge (GCD) curves of $\mathrm{NiO}$ and $\mathrm{NiO} @ \mathrm{rGO}$ nanocomposite observe at 1A/g current density shown in Fig6. Among 2, 4, 6M KOH as an electrolyte, $6 \mathrm{M} \mathrm{KOH}$ gave superior results compared to other concentrations. $\mathrm{NiO}$ and $\mathrm{NiO} @ \mathrm{rGO}$ nanocomposite's specific capacitance is found $270 \mathrm{~F} / \mathrm{g} \& 395 \mathrm{~F} / \mathrm{g}$ respectively at $1 \mathrm{~A} / \mathrm{g}$ current density. $\mathrm{NiO} @ \mathrm{rGO}$ nanocomposite showed much higher Specific capacitance than $\mathrm{NiO}$ of $6 \mathrm{M} \mathrm{KOH}$ as an electrolyte, which is also due to the nanocomposite structures' high specific surface area. The Specific capacitances decrease gradually with an increase in discharge current density that indicates variation in the number of ions accumulated within the double layers.
The working electrodes $\mathrm{NiO}$ and $\mathrm{NiO} @ \mathrm{rGO}$ present an excellent electrochemical performance at $6 \mathrm{M} \mathrm{KOH}$ electrolyte concentration. This observation is due to the activation of electrode performance related to the kinetic process. In this process, the electrical conductivity of electrolyte concentration plays a vital role. The fact that conductivity generally increases with its concentration in aqueous solutions and this conductivity maximum at $6 \mathrm{M} \mathrm{KOH}$ electrolyte concentration ${ }^{[22,23]}$ and more enough $\mathrm{OH}^{-}$ion concentrations then $2 \mathrm{M}$ and $4 \mathrm{M} \mathrm{KOH}$ concentration, it facilitates penetration of electrolyte ion into an electrode, which improves the charge transfer in the bulk electrolyte and electrode ${ }^{[11]}$. 


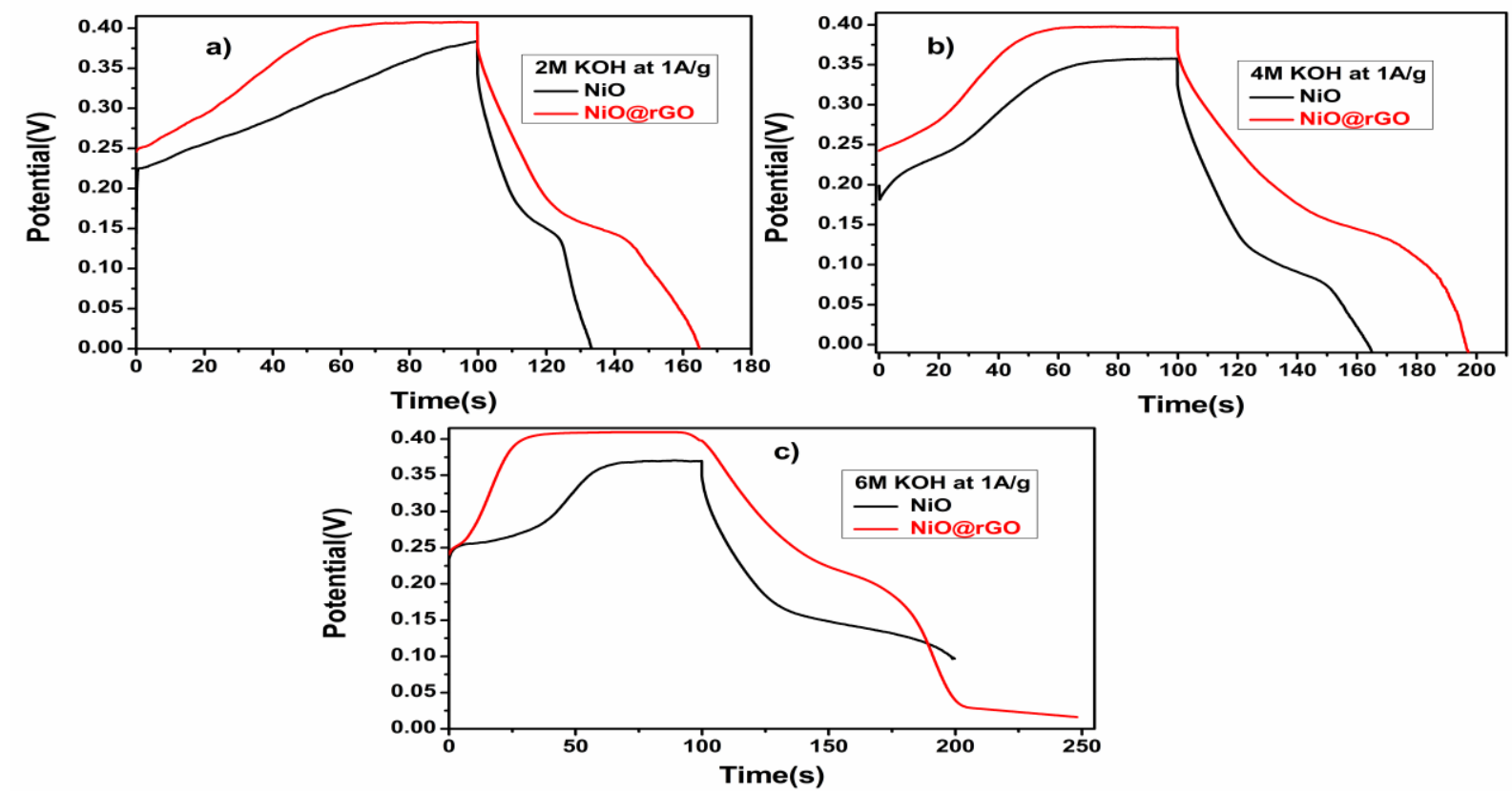

Fig6: a) GCD of $\mathrm{NiO} \& \mathrm{NiO} @ \mathrm{rGO}$ at $2 \mathrm{M} \mathrm{KOH.} \mathrm{b)} \mathrm{GCD} \mathrm{of} \mathrm{NiO} \& \mathrm{NiO} @ \mathrm{rGO}$ at $4 \mathrm{M} \mathrm{KOH}$. c) GCD of $\mathrm{NiO}$ \&NiO@rGO at 6M KOH as an electrolyte.

The specific capacitance calculated from GCD studies used the formula :

$$
\mathrm{Csg}=\frac{\mathrm{I} \times \Delta \mathrm{t}}{\mathrm{m} \times \Delta \mathbf{V}}
$$

Where $\mathrm{Cs}_{\mathrm{g}}$ is Specific capacitance $(\mathrm{F} / \mathrm{g})$, $\mathrm{m}$ is the mass of material coated on an electrode $(\mathrm{mg}), \Delta \mathrm{V}$ is potential difference $(\mathrm{V}), \Delta \mathrm{t}$ is discharge time(s).

The Energy density is the amount of energy to be stored in Supercapacitor, the energy density of $10.2 \mathrm{Wh} / \mathrm{Kg}$ and 17.6 $\mathrm{Wh} / \mathrm{Kg}$ for $\mathrm{NiO}$ and $\mathrm{NiO} @ \mathrm{rGO}$ nanocomposites, respectively, were observed at $1 \mathrm{~A} / \mathrm{g}$ current density from charge-discharge curves of $6 \mathrm{M} \mathrm{KOH}$ as an electrolyte.

Energy density (E) obtained from the galvanostatic test derived from the following equation:

$$
\mathbf{E}==\frac{\left.\operatorname{Csg} \times(\Delta \mathbf{V})^{2}\right)}{8}
$$

Where $\mathrm{Cs}_{\mathrm{g}}$ is Specific capacitance $(\mathrm{F} / \mathrm{g}), \mathrm{E}$ is Energy density ( $\mathrm{Wh} / \mathrm{Kg}), \Delta \mathrm{V}$ is the potential difference $(\mathrm{V})$.
Specific capacitance and Energy densities of $\mathrm{NiO} \&$ NiO@rGO nanocomposites show in Table2.

Table2: Specific capacitance and Energy densities of NiO Nanostructures \&NiO@rGO nanocomposites.

\begin{tabular}{|l|l|l|}
\hline Material & $\begin{array}{l}\text { Specific } \\
\text { capacitance } \\
(\mathbf{F} / g) \text { at } \mathbf{1 A} / \mathbf{g}\end{array}$ & $\begin{array}{l}\text { Energy } \\
\text { density } \\
(\mathbf{W h} / \mathbf{K g})\end{array}$ \\
\hline $\mathrm{NiO} 2 \mathrm{M}$ & 88 & 3.5 \\
\hline $\mathrm{NiO} @ \mathrm{rGO} 2 \mathrm{M}$ & 160 & 7.4 \\
\hline $\mathrm{NiO} 4 \mathrm{M}$ & 173 & 6.2 \\
\hline $\mathrm{NiO} @ \mathrm{rGO} 4 \mathrm{M}$ & 250 & 11.1 \\
\hline $\mathrm{NiO} 6 \mathrm{M}$ & 270 & 10.2 \\
\hline $\mathrm{NiO} @ \mathrm{rGO} 6 \mathrm{M}$ & 395 & 17.6 \\
\hline
\end{tabular}

Conclusion: In this study, Nano circular plate structured Nickel Oxide(NiO) and Nickel Oxide @ reduced Graphene Oxide(NiO@rGO) nanocomposite materials prepared by microwave irradiation method. To verify the successful 
preparation of nanomaterials and calcined temperature TG analysis performed. Characteristic analysis for structural and morphological studies carried by XRD, and FESEM micrographs at different magnifications, has been noted as sphere-shaped with an average diameter of $\sim 72 \mathrm{~nm}$ and thickness of $\sim 10 \mathrm{~nm}$. An increase in the specific surface area from BET for NiO@rGO nanocomposite leads to an enhancement in Electrochemical specific capacitance due to its direct effect on the reaction sites. The electrochemical analysis was performed by CV, GCD, and EIS at three different molarities (2M, 4M \& 6M) with potassium hydroxide( $\mathrm{KOH})$ as an electrolyte. From $\mathrm{CV}$ analysis by an increase in scan rate, there is a decrement in specific capacitance and an increase in the concentration of electrolytes; there is an increment of Specific capacitance for both $\mathrm{NiO}$ and $\mathrm{NiO} @ \mathrm{rGO}$ nanocomposite. The GCD study observed that specific capacitances at $1 \mathrm{~A} / \mathrm{g}$ are $270 \mathrm{~F} / \mathrm{g} \& 395 \mathrm{~F} / \mathrm{g}$, and Energy densities are 10.2Wh/Kg $\& 17.5 \mathrm{Wh} / \mathrm{Kg}$ for $\mathrm{NiO}$ and $\mathrm{NiO} @ \mathrm{rGO}$ nanocomposite respectively at $6 \mathrm{M} \mathrm{KOH}$ as an electrolyte.

Electrochemical behavior increased due to the nano-size and high specific surface area of the nanocomposite structures. The current study concludes as the addition of Carbon composite to metal oxides improves the surface area with increases in Specific capacitance and energy density for better energy storage Supercapacitors.

\section{Acknowledgment:}

This work has been supported in part by DST Project

Central Government Fundamental Research Funds (no.

SERB/F/7867/2019-2020).

\section{References}

1. US20130089769A1.pdf.

2. Zhao, B. et al. Monolayer graphene/NiO nanosheets with two-dimension structure for supercapacitors. J. Mater. Chem. 21, 18792-18798 (2011).

3. Mallikarjuna, K. et al. Phytogenic synthesis of Pd$\mathrm{Ag} / \mathrm{rGO}$ nanostructures using stevia leaf extract for photocatalytic $\mathrm{H} 2$ production and antibacterial studies. Biomolecules 11, 1-15 (2021).

4. Yadav, S. \& Devi, A. Recent advancements of metal oxides/Nitrogen-doped graphene nanocomposites for supercapacitor electrode materials. Journal of Energy Storage vol. 30 (2020).

5. Vijayakumar, S., Nagamuthu, S. \& Muralidharan, G. Supercapacitor studies on $\mathrm{NiO}$ nanoflakes synthesized through a microwave route. ACS Appl. Mater. Interfaces 5, 2188-2196 (2013).

6. Nam, K. W. et al. Pseudocapacitive properties of electrochemically prepared nickel oxides on 3dimensional carbon nanotube film substrates. $J$. Power Sources 182, 642-652 (2008).

7. Zheng, Y. zhen, Ding, H. yang \& Zhang, M. lin. Preparation and electrochemical properties of nickel oxide as a supercapacitor electrode material. Mater. Res. Bull. 44, 403-407 (2009).

8. Wang, K., Li, L. \& Zhang, H. A novel synthesis of nickel oxide and its electrochemical performances. Int. J. Electrochem. Sci. 8, 4785-4791 (2013).

9. Ahmed, S., Rafat, M. \& Hashmi, S. A. EFFECT OF ELECTROLYTE CONCENTRATION ON SUPERCAPACITOR PERFORMANCE OF GRAPHENE-NIO COMPOSITE.

10. Aleksandra Gavrilović-Wohlmuther, Andreas Laskos, Christian Zelger, Bernhard Gollas \& Adam Harding Whitehead. Effects of Electrolyte Concentration, Temperature, Flow Velocity and Current Density on Zn Deposit Morphology. J. Energy Power Eng. 9, 1019-1028 (2015).

11. Zhao, Y., Hao, M., Wang, Y., Sha, Y. \& Su, L. Effect of electrolyte concentration on the capacitive properties of $\mathrm{NiO}$ electrode for supercapacitors. J. Solid State Electrochem. 20, 81-85 (2016).

12. Sun, C., Sun, H., Guo, Z. \& Ge, F. The fabrication of hierarchically porous carbon-coated nickel oxide nanomaterials with enhanced electrochemical properties. J. Mater. Sci. Mater. Electron. (2020) doi:10.1007/s10854-020-04585-z.

13. Shanavas, S., Ahamad, T., Alshehri, S. M., Acevedo, R. \& Anbarasan, P. M. A facile microwave route for fabrication of $\mathrm{NiO} / \mathrm{rGO}$ hybrid sensor with efficient $\mathrm{CO} 2$ and acetone gas sensing performance using clad modified fiber optic method. Optik (Stuttg). 226, 165970 (2021).

14. Prabhu, Y. T., Rao, K. V., Kumar, V. S. S. \& Kumari, B. S. X-Ray Analysis by Williamson-Hall and Size-Strain Plot Methods of $\mathrm{ZnO}$ Nanoparticles with Fuel Variation. World J. Nano Sci. Eng. 04, 21-28 (2014).

15. Bhosale, M. A. \& Bhanage, B. M. Rapid synthesis of nickel oxide nanorods and its applications in 
catalysis. Adv. Powder Technol. 26, 422-427

(2015).

16. Mironova-Ulmane, N. et al. Raman scattering in nanosized nickel oxide NiO. J. Phys. Conf. Ser. 93, 0-5 (2007).

17. Sobon, G. et al. Graphene Oxide vs Reduced Graphene Oxide as saturable absorbers for Erdoped passively mode-locked fiber laser. Opt. Express 20, 19463 (2012).

18. Hidayah, N. M. S. et al. Comparison on graphite, graphene oxide and reduced graphene oxide: Synthesis and characterization. AIP Conf. Proc. 1892, (2017).

19. Zhang, X. et al. Synthesis of porous $\mathrm{NiO}$ nanocrystals with controllable surface area and their application as supercapacitor electrodes. Nano Res. 3, 643-652 (2010).
20. Wang, L. et al. In situ atomic-scale observation of grain size and twin thickness effect limit in twinstructural nanocrystalline platinum. Nat. Commun. 11, 1-9 (2020).

21. Helan, V. et al. Neem leaves mediated preparation of $\mathrm{NiO}$ nanoparticles and its magnetization, coercivity and antibacterial analysis. Results Phys. 6, 712-718 (2016).

22. Gilliam, R. J., Graydon, J. W., Kirk, D. W. \& Thorpe, S. J. A review of specific conductivities of potassium hydroxide solutions for various concentrations and temperatures. Int. J. Hydrogen Energy 32, 359-364 (2007).

23. Ruiz, F. C. et al. Effect of electrolyte concentration on the electrochemical properties of an AB5-type alloy for $\mathrm{Ni} / \mathrm{MH}$ batteries. Int. J. Hydrogen Energy 38, 240-245 (2013). 

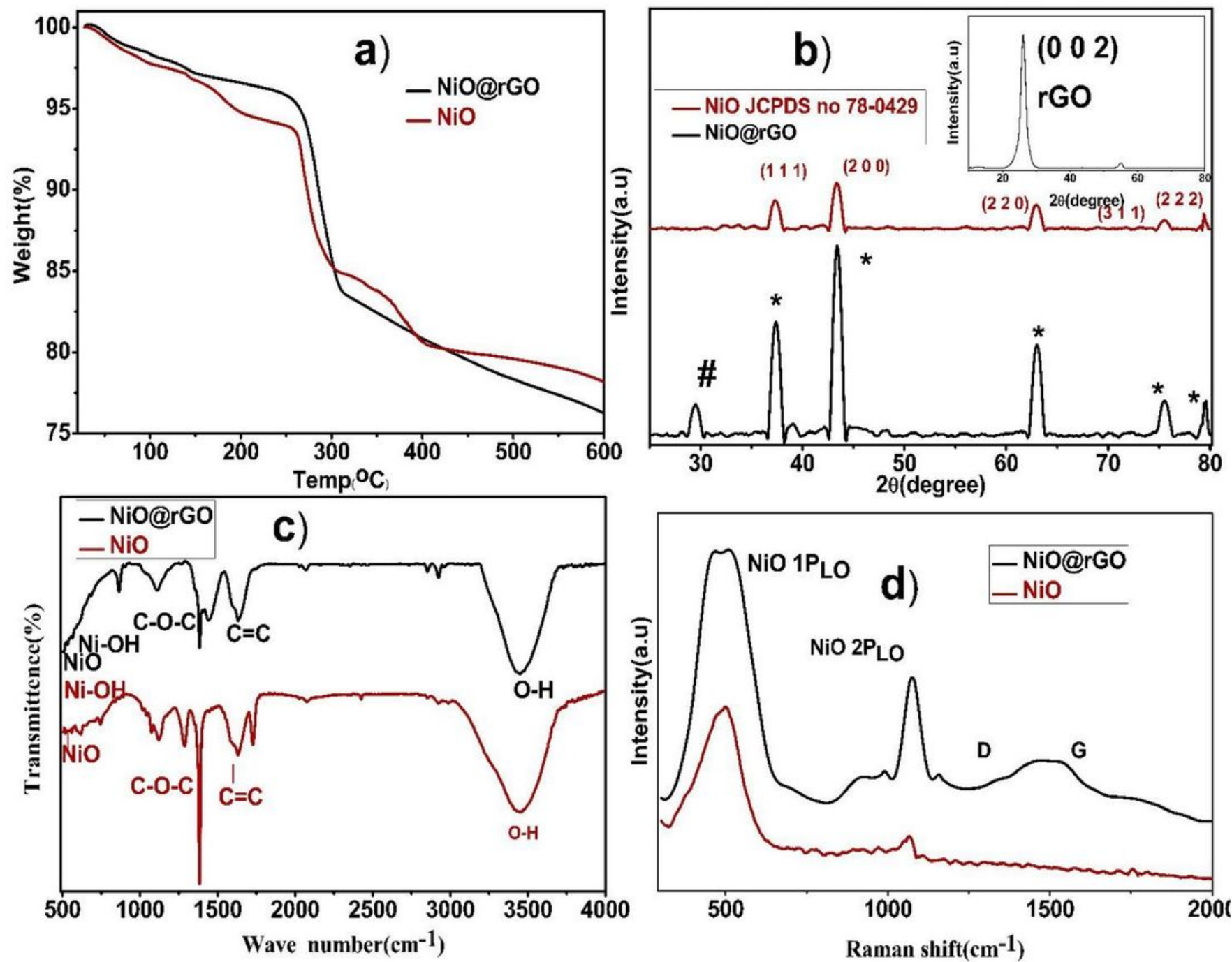

Figure 1

(a) TG spectra of NiO \& NiO@rGO (b) XRD patterns of NiO \& NiO@rGO (c) FTIR spectra of NiO \& NiO@rGO

(d) Raman spectra of NiO \& NiO@rGO nanocomposites. 


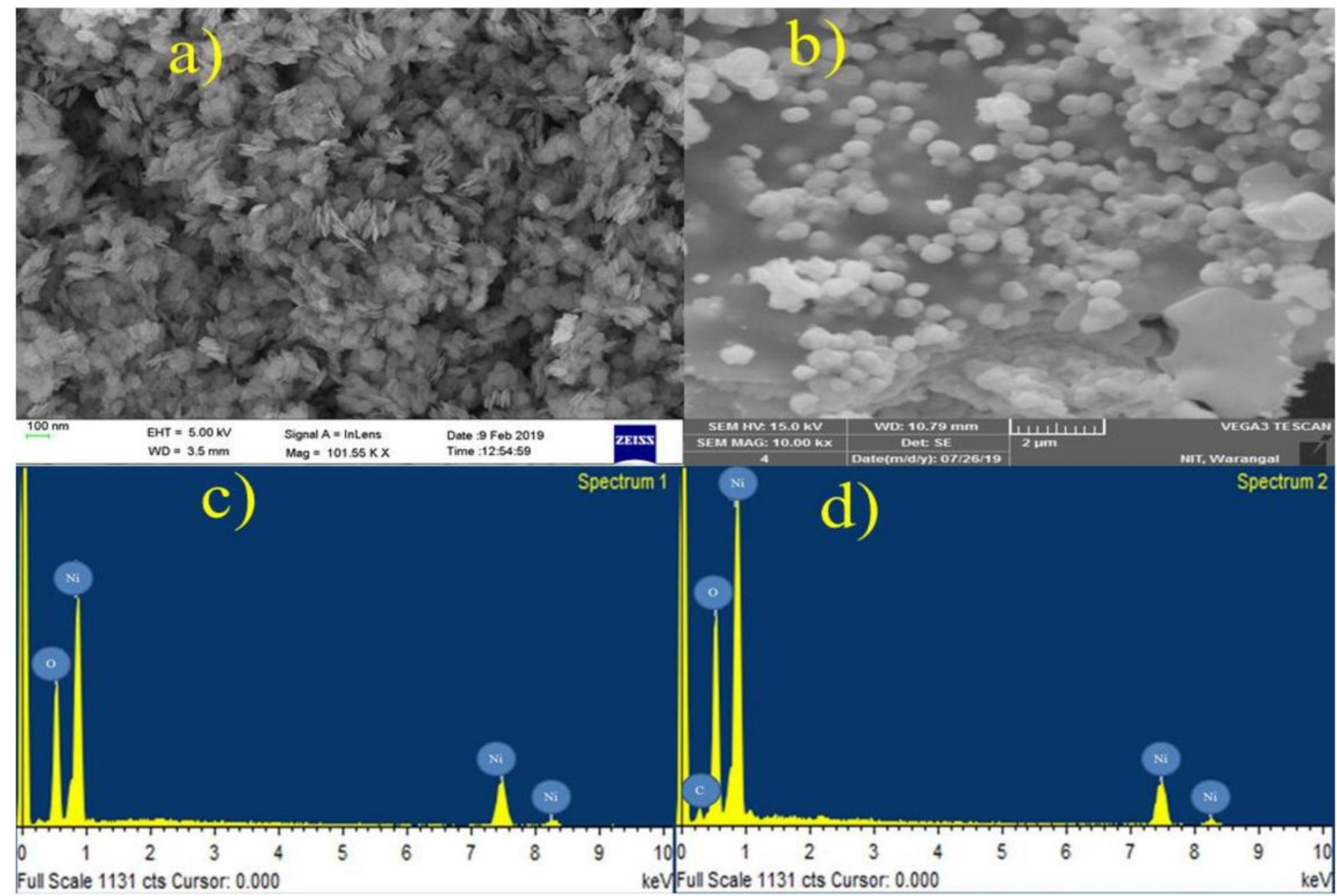

Figure 2

(a) FE-SEM NiO b) FE-SEM NiO@GO c) E-DAX NiO (d) E-DAX NiO@rGO
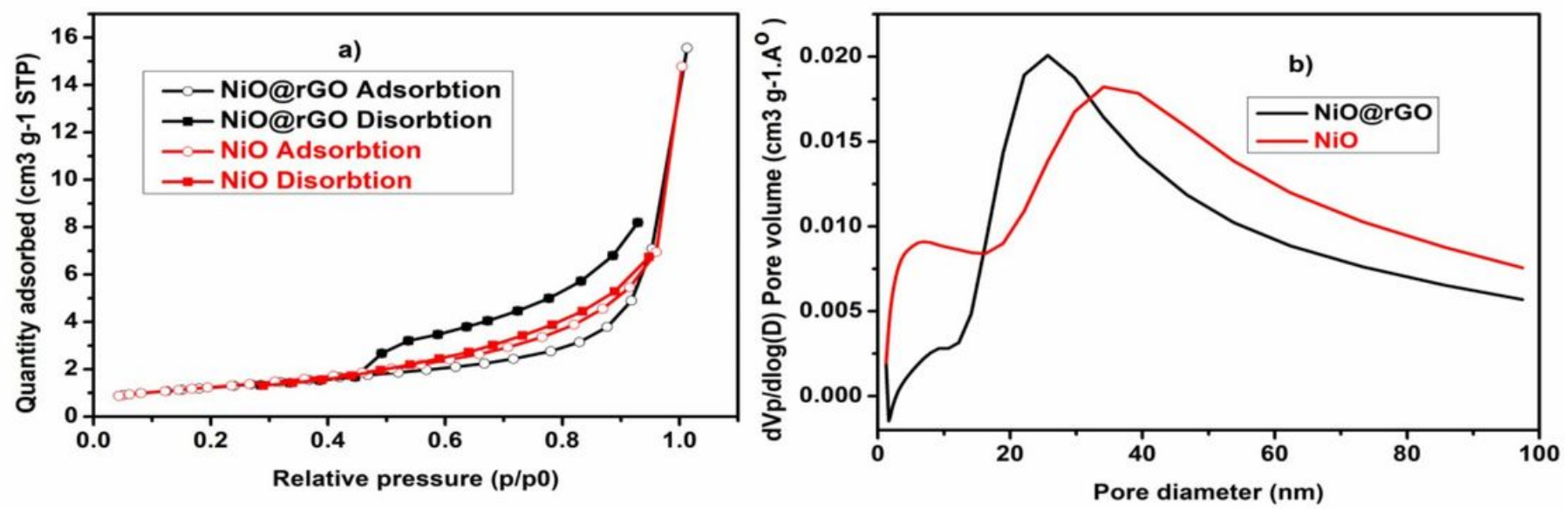

Figure 3

(a) N2 adsorption-desorption isotherm of NiO \& NiO@rGO (b) pore size distribution of NiO \& NiO@rGO 

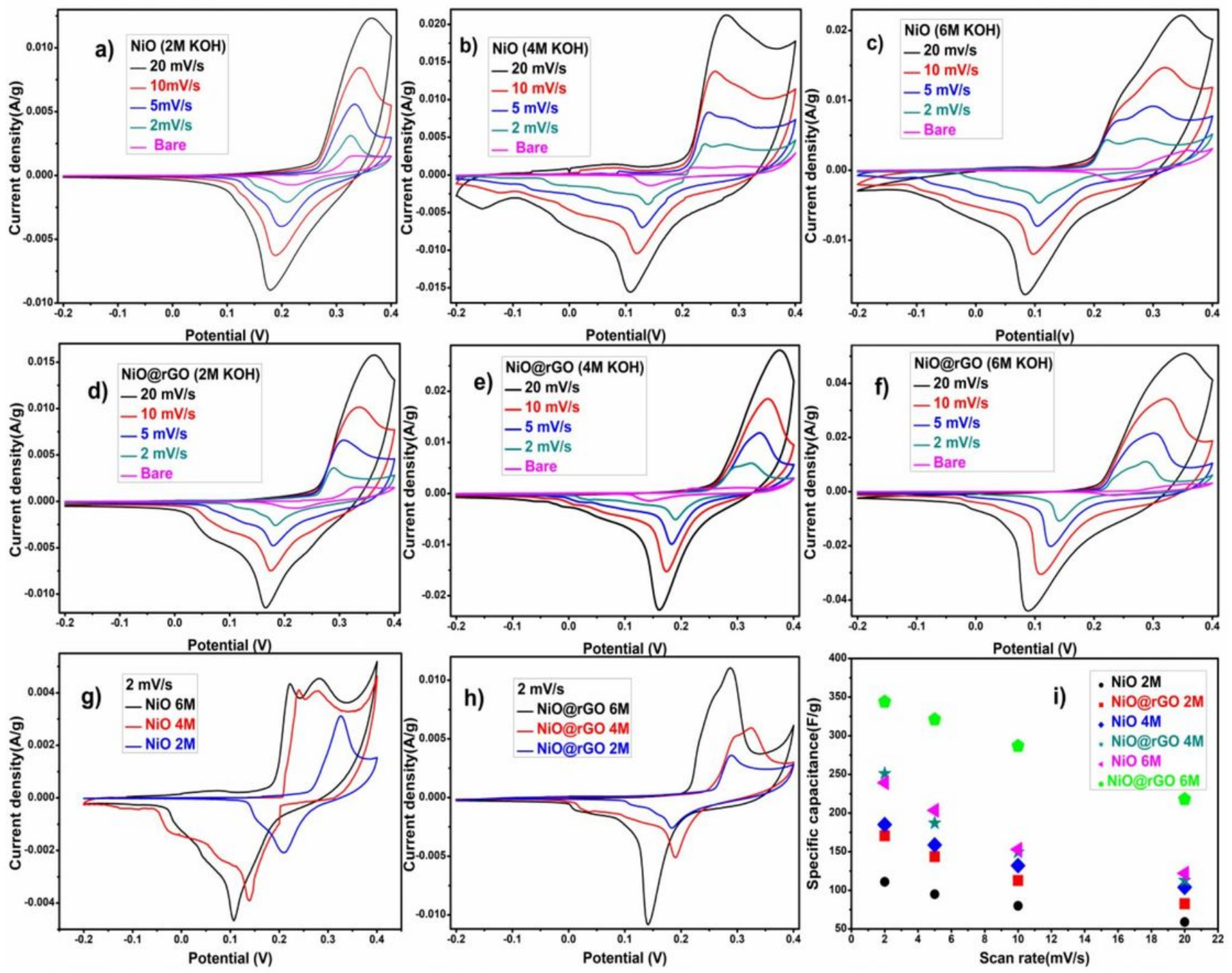

Figure 4

a),b) and c) CV of $\mathrm{NiO}$ at 2,5,10 and $20 \mathrm{mV} / \mathrm{s}$ Scan rates with $2 \mathrm{M}, 4 \mathrm{M}$ and $6 \mathrm{M}$ of $\mathrm{KOH}$ as electrolyte respectively d),e) and f) CV of $\mathrm{NiO} @ \mathrm{rGO}$ at 2,5,10 and 20mV/s Scan rates with 2M, 4M and 6M of $\mathrm{KOH}$ as electrolyte respectively g),h) CV of 20mV/s Scan rates of NiO\&NiO@rGO respectively i)Specific capacitance Vs Scan rate 


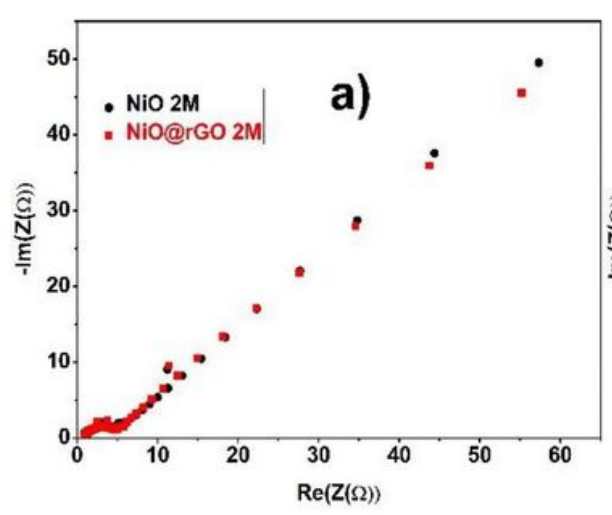

b)

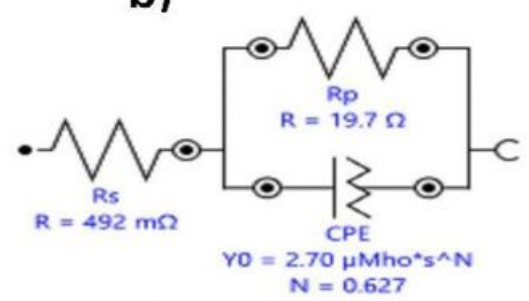

c)

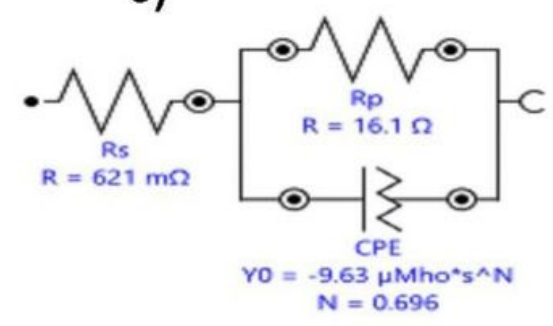

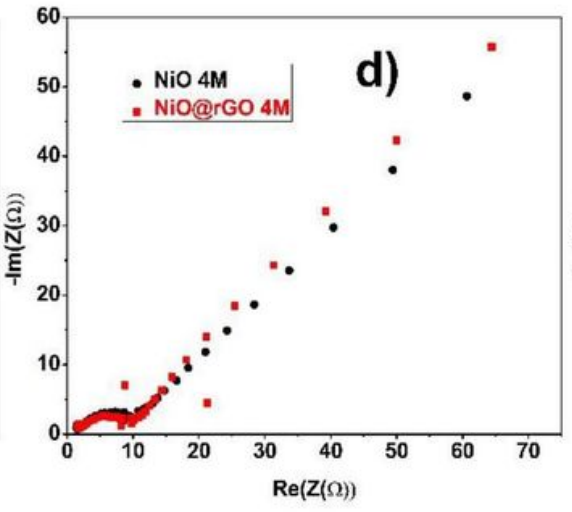

e)

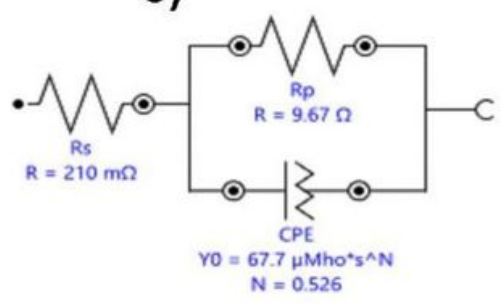

f)

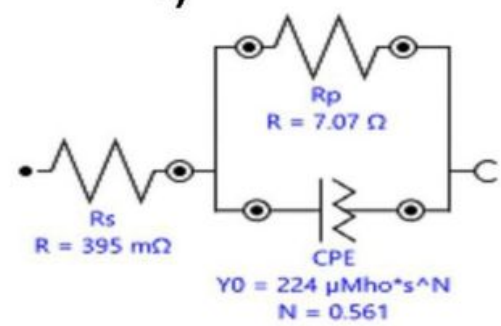

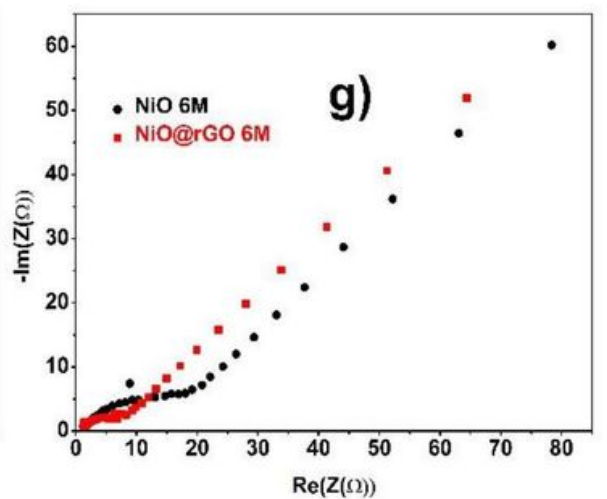

h)

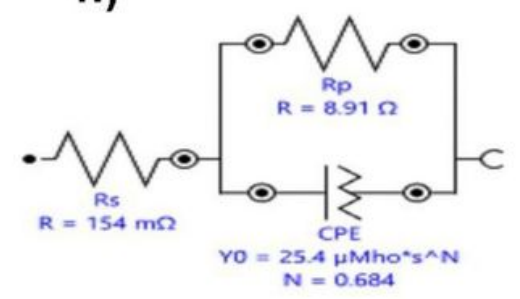

i)

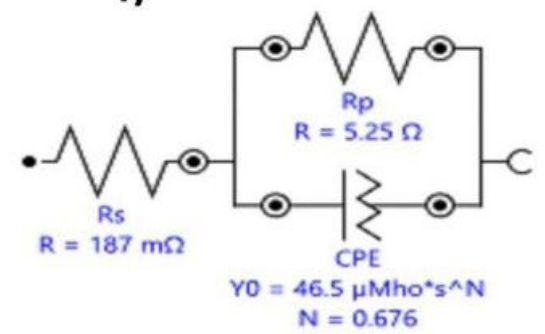

\section{Figure 5}

(a)(d)(g) EIS study of NiO \&NiO@rGO at 2,4,6M KOH as an electrolyte respectively. (b)(e)(h) Equivalent circuit NiO. (c)(f)(i) Equivalent circuit NiO@rGO at 2,4,6M KOH as an electrolyte respectively. 

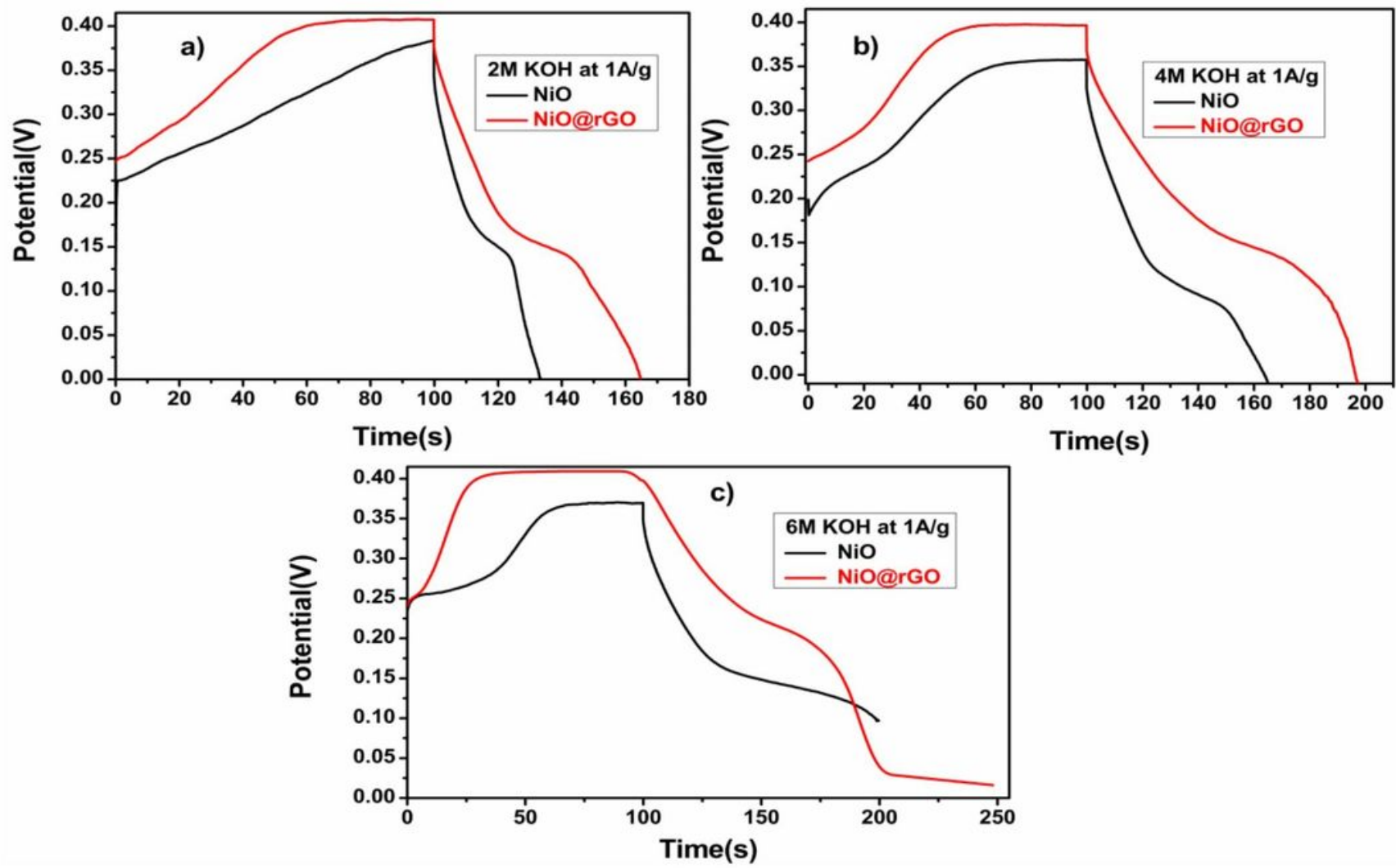

Figure 6

a) GCD of NiO \& NiO@rGO at 2M KOH. b) GCD of NiO \& NiO@rGO at 4M KOH. c) GCD of NiO \&NiO@rGO at $6 \mathrm{M} \mathrm{KOH}$ as an electrolyte

\section{Supplementary Files}

This is a list of supplementary files associated with this preprint. Click to download.

- Tables.pdf

- GraphicalAbstract.jpg 